\title{
Connecting People With Multimorbidity to Interprofes- sional Teams Using Telemedicine
}

\author{
Pauline Pariser, $M D^{1,2,3}$ \\ Thuy-Nga (Tia) Pbam, MD ${ }^{1,4}$ \\ Judith B. Brown, $P b D^{5}$ \\ Moira Stewart, $P b D^{5}$ \\ Jocelyn Charles, MD, MScCH ${ }^{1,2,6}$ \\ 'Department of Family and Community \\ Medicine, University of Toronto, Toronto, \\ Ontario, Canada \\ ${ }^{2}$ Toronto-Central Local Health Integra- \\ tion Network Toronto, Toronto, Ontario, \\ Canada \\ ${ }^{3}$ University Health Network, Toronto, \\ Ontario, Canada \\ ${ }^{4}$ South East Toronto Family Health Team, \\ Toronto, Ontario, Canada \\ ${ }^{5}$ Centre for Studies in Family Medicine, \\ Western University, London, Ontario, \\ Canada \\ ${ }^{6}$ Veterans Centre, Sunnybrook Health \\ Sciences Centre, Toronto, Ontario, Canada
}

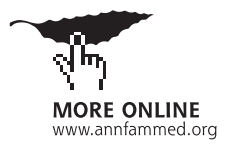

Conflicts of interest: authors report none.

\section{CORRESPONDING AUTHOR}

Jocelyn Charles, MD, MScCH Sunnybrook Health Sciences Centre 2075 Bayview Ave, Rm KGE-39 Toronto, ON Canada M4N 3M5 Jocelyn.charles@sunnybrook.ca

\begin{abstract}
PURPOSE Most models for managing chronic disease focus on single diseases. Managing patients with multimorbidity is an increasing challenge in family medicine. We evaluated the feasibility of a novel approach to caring for patients with multimorbidity, performing a case study of TIP-Telemedicine IMPACT (Interprofessional Model of Practice for Aging and Complex Treatments) Plus - a 1-time interprofessional consultation with primary care physicians (PCPs) and their patients in Toronto, Canada.
\end{abstract}

METHODS We assessed feasibility of the TIP model from the number of referrals from PCPs and emergency departments in Toronto, Canada; the intervention cost; and the satisfaction of patients, PCPs, and team members with the new model. One patient and PCP story highlights the model's impact. We also performed thematic analysis of written feedback.

RESULTS A total of 76 patients were referred from 53 PCPs and 4 emergency departments, and 65 PCPs participated in TIP. All 74 patient survey respondents indicated TIP improved their access to interdisciplinary resources, and $97 \%$ reported feeling hopeful their conditions would improve as a result. Of 21 PCP survey respondents, 100\% reported they would use TIP again, and $90 \%$ reported improved confidence in managing their patient's care. Of 87 team member survey respondents, $97 \%$ rated TIP as effective. Qualitative findings indicated benefits to both patients and health professionals. The cost was about $22 \%$ less than that of a 1-day hospital admission through the emergency department $(C \$ 854$ vs $C \$ 1,088)$.

CONCLUSIONS TIP is a feasible intervention in multiple primary care settings that gives patients an active role in their health management, supported by their team. The model effectively addresses the needs of the most complex patients and their PCPs.

Ann Fam Med 2019;17:S57-S62 https://doi.org/10.1370/afm.2379.

\section{INTRODUCTION}

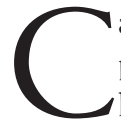
anada, like other developed countries, is facing challenges in providing cost-effective, quality care to the $5 \%$ of patients with high needs, a group that consumes the majority of health care resources. ${ }^{1-3} \mathrm{~A}$ Canadian study showed a 40\% increase between 2003 and 2009 in people living with multimorbidity, ${ }^{4}$ defined as "the co-existence of 2 or more chronic conditions, where one is not necessarily more central than the others." ${ }^{15}$ These conditions may include physical, mental health, and substance use challenges; polypharmacy; gaps in social determinants of health; and overmedicalization. ${ }^{6-9}$

An American study determined that patients with more than 3 chronic conditions were $25 \%$ to $40 \%$ more likely to report problems with care coordination..$^{10}$ A Cochrane review of management interventions delineated frequent health system users as having "high-impact multimorbidity" affecting both quality of life and use of health care services. ${ }^{11}$ It is therefore no surprise that people with multimorbidity experience poorer quality of life and lack timely, coordinated health care..$^{4,12,13}$ A systematic review of 
patient perspectives from the United States, Australia, and the United Kingdom found a link between multimorbidity and challenges in disease self-management that was related to conflicting information, access to care, and communication with health professionals. ${ }^{14}$ The study recommended that professionals adopt a more patient-centered approach that supports wholeperson care. Similarly, patients with multimorbidity have expressed that they know what they need and want to be involved in their own care. ${ }^{15}$

For primary care physicians (PCPs), there is the commensurate burden of the increasing prevalence of patients with multimorbidity in the primary care setting. ${ }^{16}$ One common limitation, cited by both patients and clinicians, is insufficient time and structure to address a myriad of interacting conditions within a typical 15 -minute appointment. ${ }^{17}$ PCPs in Canada also have variable access to interprofessional teams to assist with complex health issues (polypharmacy, psychosocial distress) and social concerns (housing, food security). Less than one-fourth of the Ontario population has access to team-based primary care. ${ }^{18}$ PCPs not affiliated with teams express frustration and concerns about burnout in caring for this growing cohort with multimorbidity. ${ }^{19}$

The current health care system was developed in response to acute illness and injury, with patients as the passive recipients of care, rather than promoting patients' self-management skills. ${ }^{20}$ The result is overmedicalization leading to fragmented, poorly coordinated care focused on single-disease protocols, multiple investigations, and specialist referrals, and addressing social determinants of health with inappropriate medical care. ${ }^{3,5}$ Alternatives to traditional serial office visits and overreliance on acute care services are therefore urgently needed for a sustainable system. ${ }^{21-24}$ Telemedicine technology is a promising solution that can virtually link PCPs and their more fragile complex patients to real-time interprofessional case consultation. ${ }^{25}$

This article describes the feasibility of a costeffective, virtual team-based model, using telemedicine for people living with multimorbidity and their PCPs, who struggle to support them in the community.

\section{METHODS}

\section{Study Context}

The IMPACT model (Interprofessional Model of Practice for Aging and Complex Treatments) was developed 10 years ago to address the need for team-based patient-centered care supporting the PCP. ${ }^{26}$ Telemedicine IMPACT Plus (TIP) built on this model by facilitating access to team-based care for community-based PCPs unaffiliated with a primary care team. TIP synchronously connects patients and their PCPs by tele- medicine in a real-time interprofessional case consultation focused on what is most important to the patient (Supplemental Figure 1, available at http://www. AnnFamMed.org/content/17/Suppl_1/S57/suppl/DC1/). A key enabler is the dedicated TIP registered nurse who meets with the PCP and the patient in advance to prioritize the issues most important to the patient. TIP provides immediate problem solving on a range of issues that put complex patients at risk; enhances self-management and care coordination; increases health care efficiencies by aligning care and goals with appropriate reductions in medications and serial specialist consultations; and equips the PCP with local resources. Telemedicine technology allows the PCP in his/her office, the patient at home, and the TIP teams, gathered together in 1 "location," to simultaneously conduct a 1-hour clinical consultation using secure videoconferencing. The TIP team is composed of specialists from psychiatry and internal medicine, as well as a social worker, pharmacist, home care and community coordinator, and other professionals as appropriate, based on the patient's needs, such as an occupational therapist or dietitian. The team develops a set of recommendations that forms the nucleus of a coordinated care plan. The TIP nurse helps with follow-through of the team's recommendations together with the patient's PCP. TIP is thus designed to produce a robust set of patient-informed recommendations that appreciates the interplay between polypharmacy, functional disability, social determinants of health, and chronic physical and mental health conditions. The TIP model has demonstrated feasibility in 2 primary care settings in Toronto. $^{26}$

\section{Study Design and Participants}

This case study aimed to assess the feasibility and satisfaction of the TIP intervention conducted with patients, referring PCPs, and participating team members (allied health care professionals and specialist physicians, eg, internal medicine, psychiatry). Case study lines of evidence were selected to provide a rich description of the feasibility and satisfaction of the TIP intervention, and included quantitative analysis of TIP uptake and satisfaction survey findings, qualitative thematic analysis of participant feedback, and a patient vignette. ${ }^{27}$

For inclusion in the TIP intervention, patients had to have 3 or more chronic conditions, be aged 18 to 80 years, and be willing to participate. Eligible patients were identified and referred by PCPs and emergency department (ED) staff, following brochure campaigns to community PCPs, and information sessions in 4 Family Health Teams and 4 EDs in 3 regions of Toronto. In addition, potentially eligible patients were identified through searches of electronic health records in 4 Fam- 
ily Health Teams (69 PCPs) and 15 community PCP practices. Patients identified through electronic health record searches were reviewed by the PCP for eligibility. Satisfaction surveys were distributed by the TIP nurse at the end of TIP clinics to patients, PCPs and TIP team members, and collected centrally.

All participating sites received full ethics approval. All participants gave written informed consent.

\section{Feasibility and Satisfaction Metrics}

Uptake of TIP was assessed from the number of referrals and from participation in TIP clinics by patients and their PCPs. The cost per patient included the nursing time to prepare, organize, and follow up with patients and PCPs, interprofessional team time, and specialist and PCP billing. We compared this cost with the estimated cost of acute care services used by this group of patients. The satisfaction of patients, $\mathrm{PCPs}$, and team members was measured after each TIP clinic, with separate questionnaires for patients (12 questions), PCPs (8 questions), and team members (6 questions), and it included a mix of 2 open-ended questions and 4 (team member questionnaire), 6 (PCP questionnaire), or 7 (patient questionnaire) "rate your agreement" questions on a 4-point Likert scale. Questionnaires were distributed in person and completed at the end of the TIP clinic (Supplemental Appendix, available at http://www. AnnFamMed.org/content/17/Suppl_1/S57/suppl/DC1/).

We compiled a database of patient, PCP, and team member feedback, and recorded in the database comments from open-ended survey questions or spontaneously shared by patients, PCPs, and team members. This database was reviewed to conduct a thematic analysis of frequent comments related to uptake or satisfaction.

The vignette patient was selected by conducting an informal review of TIP patients to identify an individual with complex multimorbidities whose experience was thematically similar to that of other TIP patients. Descriptive analysis was used to present the patient vignette. ${ }^{27}$

\section{RESULTS}

\section{Study Sample}

A total of 129 PCPs from 4 Family Health Teams and 280 local community PCPs were informed about the program. Of these, $53 \mathrm{PCPs}$ referred patients and participated in the TIP intervention, and an additional 12 PCPs participated in TIP after their patients were referred by ED staff. Seventy-six patients participated in a TIP case conference with 1 of 12 interprofessional teams at 9 sites (hospitals and primary care clinics) over a period of 1 year. All 76 patients had multimorbidity; $65 \%$ were female, and the average age was 66 years.
The majority (72\%) were aged older than 60 years, and a sizable minority (19\%) were aged older than 80 years.

\section{Satisfaction Surveys}

The results of the satisfaction surveys demonstrated high levels of satisfaction with the TIP intervention across all 3 participant groups (Table 1).

\section{Written Feedback}

Thematic analysis of the written feedback revealed how each participating group (patients, referring PCPs, and team members) benefited from participation in the TIP model. Feedback from the PCPs reflected how they felt validated and supported by TIP discussions. PCPs described how TIP improved their rapport with their patients and offered further insight into their patient's behaviors and disease. PCPs and team members identified and appreciated the efficiency of consultation with multiple specialists at once. They also highlighted collaboration and interprofessional learning as key benefits of the TIP consultations. Patients, their family members, PCPs, and team members noted that TIP enhanced the relationship between PCP and patients. Several patients shared that they felt a renewed sense of empowerment over their own health and attributed this to the TIP intervention.

Several team members suggested that agenda setting could improve efficiency of TIP team discussions. A few team members had challenges with their telephone or screen connections, and emphasized the need for easy-to-use communication technologies. Overall, the written qualitative feedback demonstrated a

\section{Table 1. Participants' Satisfaction With the TIP Intervention}

\begin{tabular}{|c|c|}
\hline Survey Item & $\begin{array}{c}\text { Respondents } \\
\text { Who Agreed } \\
\text { or Strongly } \\
\text { Agreed, \% }\end{array}$ \\
\hline \multicolumn{2}{|l|}{ Patients $(n=74)$} \\
\hline $\begin{array}{l}\text { TIP has effectively improved my access to new } \\
\text { interdisciplinary resources }\end{array}$ & 100 \\
\hline $\begin{array}{l}\text { I am hopeful that my chronic condition will } \\
\text { improve as a result of the TIP case conference }\end{array}$ & 97 \\
\hline \multicolumn{2}{|l|}{ Primary care physicians $(n=21)$} \\
\hline $\begin{array}{l}\text { I would use telemedicine technology again to } \\
\text { facilitate a case conference }\end{array}$ & 100 \\
\hline $\begin{array}{l}\text { TIP case conference increased my confidence in } \\
\text { managing this patient's chronic care }\end{array}$ & 90 \\
\hline \multicolumn{2}{|l|}{ Team members $^{\mathrm{a}}(\mathrm{n}=87)$} \\
\hline $\begin{array}{l}\text { The TIP case conference was an effective model } \\
\text { to develop a care plan for this complex patient }\end{array}$ & 97 \\
\hline \multicolumn{2}{|c|}{$\begin{array}{l}\text { IMPACT = Interprofessional Model of Practice for Aging and Complex Treat- } \\
\text { ments; TIP = Telemedicine IMPACT Plus. }\end{array}$} \\
\hline \multicolumn{2}{|c|}{$\begin{array}{l}\text { a Team members included allied health care professionals and specialist } \\
\text { physicians. }\end{array}$} \\
\hline
\end{tabular}


positive impact on patients, their PCPs, and specialist members of the interdisciplinary team. Specifically, there was congruence between the perceptions of patients and the perceptions of PCPs that the TIP model effectively addressed the needs of complex patients.

\section{Patient Vignette}

Ms HP*, a 45-year-old

Mandarin-speaking single woman living with her parents, visited a Toronto ED 70 times during 2 years. When asked why she visited so often, she replied, "When I hear voices in my head, I don't want to be alone."

Her medical history included lung and bilateral breast cancer, schizophrenia, and constipation. She had delusions that her bloated abdomen was due to a pregnancy, and she could feel "a baby moving inside of [her]." She had not completed high school, was not employed, and received social assistance. She had a Mandarin-speaking family physician who did not have access to a team and could schedule only 15 -minute appointments, as well as a community psychiatrist whom she saw every 3 weeks for antipsychotic injections.

Her family physician was alerted to her frequent ED visits, was offered a TIP consultation, and was eager to participate. Before the consultation, a TIP nurse reviewed the patient's medical record, spoke via telephone with the patient's family physician, and conducted a preconsult interview with the patient in her home. A pharmacist, social worker, psychiatrist, general internist, home and community care coordinator, and registered nurse health coach participated in the TIP consultation via secure videoconferencing.

The TIP consultation began with the team asking the patient for her top 3 health-related priorities. The team subsequently discussed recommendations for the patient, including strategies to address her anxiety, attachment to a health coach to call if she was becoming anxious, and education on how to better manage her chronic constipation. The family doctor also offered more flexible hours for drop-in support. The health coach connected her with day programs and a mental health team. After the TIP consultation, Ms HP has visited the ED only 3 times in 6 months, twice when the health coach was out of town and

*Ms HP provided written consent to share ber case once when she forgot to take prophylactic medication for constipation.

\section{Estimated Intervention Cost}

The average cost for the TIP intervention calculated for 40 patients, shown in Table 2, is substantially less than that of a 1-day hospital admission. The interprofessional teams were provided in kind by 6 acute care hospitals and 1 rehabilitation hospital, 4 family health teams, and 2 community agencies, as these were salaried employees whose TIP work was embedded in existing team activities. Telemedicine equipment was mostly preexisting.

\section{DISCUSSION}

Our results demonstrate that TIP is a feasible new model of care in primary care settings that gives patients an active role in the management of their health care, supported by their care team. The model has shown the ability to effectively and efficiently address the needs of the most complex patients and their PCPs.

The limitations of this study include uncertain generalizability to other health care systems, particularly those without access to portable and secure videoconferencing, and those in which funding of specialists and teams does not support collaboration with community-based PCPs. Given that the model builds and connects existing components of most health care systems and addresses a common challenge of coordinating care for patients with multimorbidity, it is an efficient model. Although this study does not measure the effectiveness of the intervention, the cost of the intervention is less than that of a 1-day admission to 
the hospital through the ED. Based on available case report data, it is anticipated that this intervention is a cost-effective initiative that will reduce ED visits and hospital admissions through enhanced care coordination. ${ }^{28,29}$ Long-term follow-up of patients post-TIP to evaluate health system use is in progress.

The TIP model achieves synchronous connection of patients with multimorbidity and their PCPs in an interprofessional case consultation focused on what is most important to the patient. TIP is an efficient model that integrates patient, PCP, and an interdisciplinary team focused simultaneously on disease management and the integration of biopsychosocial needs, resulting in an enhanced understanding of the patient's context and goals. Patient acceptance of different strategies is immediately evident, allowing for more appropriate interventions to be developed during the session. TIP facilitates patient-to-clinician and clinician-to-clinician communication, which are essential to an integrated health care system. The results are multidimensional problem solving on a range of complex issues important to the patient, and a shared coordinated-care plan that everyone agrees on. The TIP model is therefore well aligned with the recommendations from the Institute of Medicine $^{30}$ and the Future of Family Medicine Report. ${ }^{31}$

The sustainability and dissemination of the TIP model requires a clear and efficient process to identify and invite patients with multimorbidity to participate on an ongoing basis. As these patients interact with multiple sectors of the system, this identification process can involve primary care, the ED, or acute and specialty care, or some combination thereof. Different processes have been tested for patient identification with variable success. Relying on clinicians in a traditional care model to refer to this innovative model depends on the knowledge and previous experience of the referring PCP. ${ }^{32}$ Automatic flagging systems within electronic health records that identify potential patients and bring them to the attention of a clinician have the potential to be successful. ${ }^{33}$

Another key requirement is engagement of PCPs. Taking an hour out of a busy day to participate in a TIP consultation needs to be remunerated appropriately, and scheduling needs to be flexible to accommodate the clinical demands on a busy clinician's time. Furthermore, there may be a hurdle for PCPs if they perceive these patients as difficult, tend to avoid addressing this discomfort, and fear their care methods may be criticized. ${ }^{34}$

The process of engaging teams and specialists to participate has been most successful when added to their existing clinical team meetings. Teams that have carved out set times within their schedules facilitate efficient booking. Team members committed to non- hierarchical working relationships, honoring broad perspective scopes of practice, are more adept at this synergistic type of problem solving. ${ }^{35-38}$ In fact, TIP is an excellent living example of successful interprofessional collaboration as set out by the Canadian National Competency Framework, where the goal of interprofessional collaboration is defined as a "partnership between a team of health providers and a client in a participatory, collaborative and coordinated approach to shared decision-making around health and social issues." ${ }^{\text {"39 }}$ TIP exemplifies true patient-family-community-centered care, and in this domain, it meets all the published competencies, where clinicians honor and integrate the needs and input of patients and their families in the ultimate design of the agreed-on care plan.

In conclusion, TIP is a potential vehicle to bring an interprofessional team to the family physician's doorstep. It is an innovative, efficient, and patient-centered practice model that effectively supports PCPs and their patients with multimorbidity in real time. In unpacking the complex mix of patients' conditions, TIP provides clarity and direction for integrated and coordinated care planning.

To read or post commentaries in response to this article, see it online at http:I/www.AnnFamMed.org/content/17/Suppl_1/S57.

Key words: multimorbidity; chronic disease; primary care; care coordination; integrated care; interprofessional relations; health care use; health information technology; health care team; practice-based research; telemedicine; primary care; patient-centered care; interdisciplinary health team

Submitted August 31, 2018; submitted, revised, November 12, 2018; accepted December 27, 2018.

Author contributions: P.P., J.C., T-N.(T.)P. were involved with the design, implementation, and satisfaction evaluation of the intervention. P.P. wrote the first draft of the manuscript and all authors contributed to editing all drafts, including the final draft. P.P. oversaw data collection. J.B.B. and M.S. contributed to that portion of the manuscript. J.C. oversaw manuscript production.

Funding support: The local health authority-the Ontario Local Health Integration Network (LHIN) - funded TIP. The remaining project funding was local in-kind contributions. Dr Moira Stewart was funded by the Dr Brian W. Gilbert Canada Research Chair in Primary Health Care Research (2003-2017).

Disclaimer: LHIN had no role in the design, analysis, or interpretation of the data; writing of the manuscript; or decision to submit it. These decisions were made by the clinical leads and the research team.

Previous presentations: An oral presentation of this study, "We Have a TIP for You! - Serving Complex Patients through Telemedicine IMPACT PLUS (TIP) Case Conferences," was presented at the International Conference on Integrated Care; May 23-25, 2018; Utrecht, The Netherlands, and an oral presentation was given at the North American Primary Care Research Group Annual Meeting; November 11, 2018; Chicago, Illinois.

Acknowledgments: The authors thank Erika Bennett and Heather Davidson for their editorial assistance; Frances Simone for her oversight of TIP; and all of the patients, primary care physicians, TIP nurses, and teams who participated in TIP. 
Supplementary materials: Available at http://www.AnnFamMed. org/content/17/Suppl_1/S57/suppl/DC1/.

\section{References}

1. Wodchis WP, Austin P, Newman A, Corallo A, Henry D. The concentration of health care spending: little ado (yet) about much (money). Presented at Canadian Association for Health Services and Policy Research Conference; May 30, 2012; Montreal, Canada. https://www.cahspr.ca/en/presentation/5244423937dee8014beea 024. Accessed Apr 10, 2019.

2. Salzberg CA, Hayes SL, McCarthy D, et al. Health system performance for the high-need patient: a look at access to care and patient care experiences. Issue Brief (Commonw Fund). 2016;27:1-12.

3. Vetrano DL, Calderón-Larrañaga A, Marengoni A, et al. An international perspective on chronic multimorbidity: approaching the elephant in the room. J Gerontol A Biol Sci Med Sci. 2018;73(10): 1350-1356.

4. Pefoyo AJK, Bronskill SE, Gruneir A, et al. The increasing burden and complexity of multimorbidity disease epidemiology. BMC Public Health. 2015;15(1):415-426.

5. Boyd CM, Fortin M. Future of multimorbidity research: How should understanding of multimorbidity inform health system design? Public Health Rev. 2010;32(2):451-474.

6. de Jonge P, Huyse FJ, Stiefel FC. Case and care complexity in the medically ill. Med Clin North Am. 2006;90(4):679-692.

7. Roland M, Paddison C. Better management of patients with multimorbidity. BMJ. 2013;346: f2510.

8. Kern LM, Seirup JK, Casalino LP, Safford MM. Healthcare fragmentation and the frequency of radiology and other diagnostic tests: a cross-sectional study. J Gen Intern Med. 2017;32(2):175-181.

9. Fortin M, Bravo G, Hudon C, Lapointe L, Dubois MF, Almirall J. Psychological distress and multimorbidity in primary care. Ann Fam Med. 2006;4(5):417-422.

10. Maeng DD, Martsolf GR, Scanlon DP, Christianson JB. Care coordination for the chronically ill: understanding the patient's perspective. Health Serv Res. 2012;47(5):1960-1979.

11. Smith SM, Wallace $E$, O'Dowd T, Fortin M. Interventions for improving outcomes in patients with multimorbidity in primary care and community settings. Cochrane Database Syst Rev. 2016;3:CD006560.

12. Burgers JS, Voerman GE, Grol R, Faber MJ, Schneider EC. Quality and coordination of care for patients with multiple conditions: results from an international survey of patient experience. Eval Health Prof. 2010;33(3):343-364.

13. Fortin M, Lapointe L, Hudon C, Vanasse A, Ntetu AL, Maltais D. Multimorbidity and quality of life in primary care: a systematic review. Health Qual Life Outcomes. 2004;2:51.

14. Liddy C, Blazkho V, Mill K. Challenges of self-management when living with multiple chronic conditions: systematic review of the qualitative literature. Can Fam Physician. 2014;60(12):1123-1133.

15. Bayliss EA, Edwards AE, Steiner JF, Main DS. Processes of care desired by elderly patients with multimorbidities. Fam Pract. 2008; 25(4):287-293.

16. Fortin M, Hudon C, Haggerty J, Akker Mv, Almirall J. Prevalence estimates of multimorbidity: a comparative study of two sources. BMC Health Serv Res. 2010;10(1):111.

17. Smith $\mathrm{ML}$, Bergeron $\mathrm{CD}$, Adler $\mathrm{CH}$, et al. Factors associated with healthcare-related frustrations among adults with chronic conditions. Patient Educ Couns. 2017;100(6):1185-1193.

18. Kiran T, Kopp A, Moineddin R, Glazier RH. Longitudinal evaluation of physician payment reform and team-based care for chronic disease management and prevention. CMAJ. 2015;187(17):E494-E502.

19. Ghorob A, Bodenheimer T. Sharing the care to improve access to primary care. N Engl J Med. 2012;366(21):1955-1957.
20. Wagner EH, Austin BT, Davis C, Hindmarsh M, Schaefer J, Bonomi A. Improving chronic illness care: translating evidence into action. Health Aff (Millwood). 2001;20(6):64-78.

21. Atun R. Transitioning health systems for multimorbidity. Lancet. 2015;386(9995):721-722.

22. Wilson MG, Lavis JN, Gauvin FP. Designing integrated approaches to support people with multimorbidity: key messages from systematic reviews, health system leaders and citizens. Healthc Policy. 2016; 12(2):91-104.

23. Smith SM, Soubhi H, Fortin M, Hudon C, O'Dowd T. Managing patients with multimorbidity: systematic review of interventions in primary care and community settings. BMJ. 2012;345(7874):e5205.

24. Starfield B, Lemke KW, Bernhardt T, Foldes SS, Forrest CB, Weiner JP. Comorbidity: implications for the importance of primary care in 'case' management. Ann Fam Med. 2003;1(1):8-14

25. Nochomovitz M, Sharma R. Is it time for a new medical specialty? The medical virtualist. JAMA. 2018;319(5):437-438.

26. Tracy CS, Bell SH, Nickell LA, Charles J, Upshur REG. The IMPACT clinic: innovative model of interprofessional primary care for elderly patients with complex health care needs. Can Fam Physician. 2013; 59(3):e148-e155.

27. Harrison H, Birks M, Franklin R, Mills J. Case study research: foundations and methodological orientations. Forum Qual Soc Res. 2017; 18(1).

28. Mercer T, Bae J, Kipnes J, Velazquez M, Thomas S, Setji N. The highest utilizers of care: individualized care plans to coordinate care, improve healthcare service utilization, and reduce costs at an academic tertiary care center. J Hosp Med. 2015;10(7):419-424.

29. Bielska IA, Cimek K, Guenter D, et al. Change in health care use after coordinated care planning: a quasi-experimental study. (MAJ Open. 2018;6(2):E218-E226.

30. Committee on Quality Health Care in America, Institute of Medicine. Crossing The Quality Chasm: a New Health System for the 21st Century. Washington, DC: National Academy Press; 2001.

31. Martin JC, Avant RF, Bowman MA, et al; Future of Family Medicine Project Leadership Committee. The Future of Family Medicine: a collaborative project of the family medicine community. Ann Fam Med. 2004;2(Suppl 1):S3-S32.

32. Mery G, Wodchis WP, Bierman AS, Laberge M; Health System Performance Research Network. Caring for people with multiple chronic conditions: a necessary intervention in Ontario. https:// tspace.library.utoronto.ca/handle/1807/87372. Published Jun 2013. Accessed Apr 10, 2019.

33. Frost DW, Vembu S, Wang J, Tu K, Morris Q, Abrams HB. Using the electronic medical record to identify patients at high risk for frequent emergency department visits and high system costs. Am J Med. 2017;130(5):601.e17-601.e22.

34. Dudzinski DM, Alvarez C. Repairing "difficult" patient-clinician relationships. AMA J Ethics. 2017;19(4):364-368.

35. Nancarrow SA, Booth A, Ariss S, Smith T, Enderby P, Roots A. Ten principles of good interdisciplinary team work. Hum Resour Health 2013;11(1):19.

36. Brown JB, Lewis L, Ellis K, Stewart M, Freeman TR, Kasperski MJ. Mechanisms for communicating within primary health care teams. Can Fam Physician. 2009;55(12):1216-1222.

37. Bodenheimer T, Ghorob A, Willard-Grace R, Grumbach K. The 10 building blocks of high-performing primary care. Ann Fam Med. 2014;12(2):166-171.

38. Kotecha J, Brown JB, Han $\mathrm{H}$, et al. Influence of a quality improvement learning collaborative program on team functioning in primary healthcare. Fam Syst Health. 2015;33(3):222-230.

39. Gilbert JHV, Orchard C, Bainbridge L. A National Interprofessional Competency Framework. Vancouver, British Columbia: Canadian Interprofessional Health Collaborative; 2010. 